\title{
Comprehensive pre-operative assessment of elderly patients: a challenge for the anesthesiologist
}

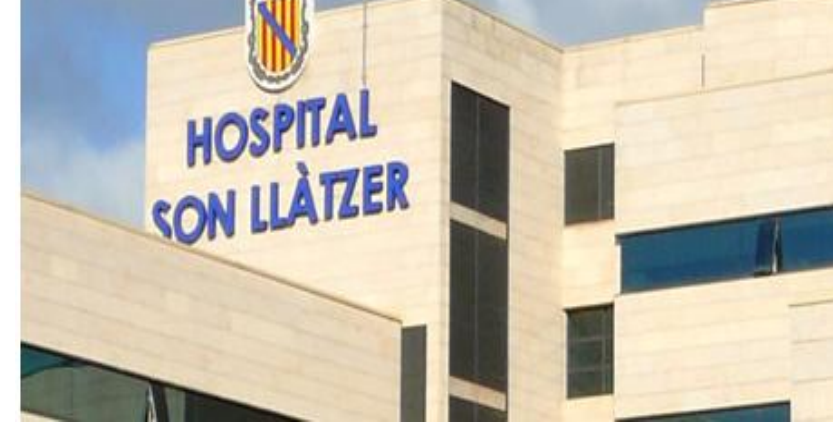

Bibiloni Molina M.I., Hernández-Puiggròs P., Gomila Sansó J.A., Nohel P., Yañez A., Aguilar J.L.

Department of Anesthesiology, Reanimation and Pain Therapeutics, Son Llàtzer Hospital, Palma de Mallorca, Islas Baleares, Spain

\section{Introduction}

Elderly patients undergoing elective surgery have a higher risk of postoperative complications due to its less functional reserve, the multimorbidities associated with polypharmacy, cognitive impairment and frailty. ${ }^{1}$

Due to continuous population aging and a concern for catering specifically to this population with its defining characteristics, the Catalan Society of Anesthesiology together with that of Geriatrics (SCARTD and SCGiG) have produced a Guide to pre-operative assessment of the elderly patient in order to offer comprehensive pre-operative advice. They recommend applying in the pre-operative evaluation the Katz questionnaires ${ }^{2}$, the Pfeiffer Test or Short Portable Mental Status Questionnaire (SPMSQ) ${ }^{3}$ and the Mini-Nutritional Assessment Short Form (MNA-SF) ${ }^{4}$ in order to assess respectively their functional, cognitive and nutrition status.

\section{Objective}

To evaluate the relationship between the pre-operative assessment guide of the Catalan Society of Anesthesiology and Geriatrics (SCARTD and SCGiG) in the elderly patient with morbidity and mortality after surgery of moderate to high risk.

\section{Methods and material}

Prospective observational study in patients aged $>70$ years or $>60$ years with associated co-morbidity scheduled for elective surgery of moderate to high aggressiveness. Data were collected from 60 patients in the pre-operative visit to whom the Katz questionnaires, the Pfeiffer Test or Short Portable Mental Status Questionnaire (SPMSQ) and the Mini-Nutritional Assessment Short Form (MNA-SF) were administered in order to assess respectively their functional, cognitive and nutrition status; with a follow-up 30 days after the intervention.

The variables were: demographic data, postoperative cognitive dysfunction (POCD), respiratory complications, cardiovascular, local and systemic infection, renal failure, endocrine-metabolic complications, hospital stay, mortality and readmission at 30 days.

\section{Results}

\begin{tabular}{|l|l|}
\hline & $\mathrm{N}=60$ \\
\hline Average age (years) & $82 \pm 8$ \\
\hline Women N (\%) & $36(60)$ \\
\hline Average hospital stay (days) & 7 \\
\hline DCPO N (\%) & $14(23,3)$ \\
\hline Respiratory complications N (\%) & $8(13,3)$ \\
\hline CV complications N (\%) & $6(10)$ \\
\hline Endocrine-metabolic complications N (\%) & $6(10)$ \\
\hline Systemic infection N (\%) & $12(20)$ \\
\hline Renal failure N (\%) & $5(8,3)$ \\
\hline 30-day mortality N (\%) & $3(5)$ \\
\hline 30-day readmission N (\%) & $7(11,7)$ \\
\hline
\end{tabular}

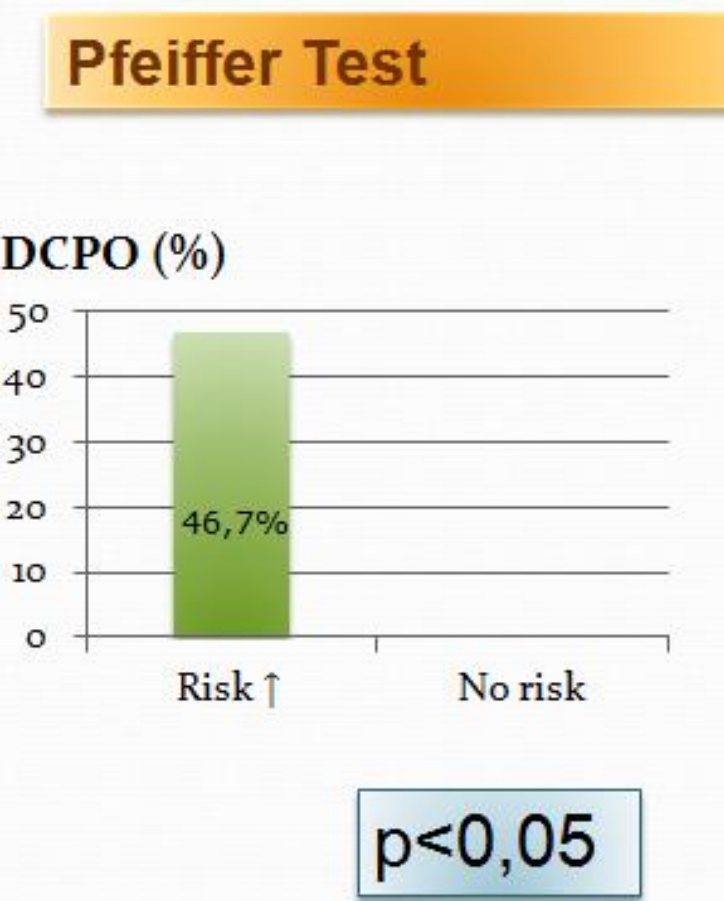

CV Complications (\%)

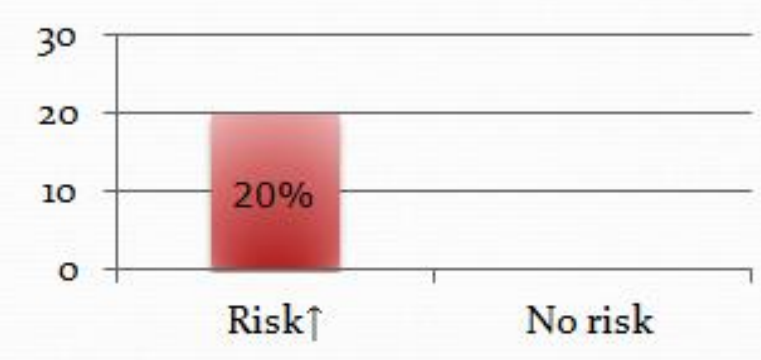

30-day Readmission

$(\%)$

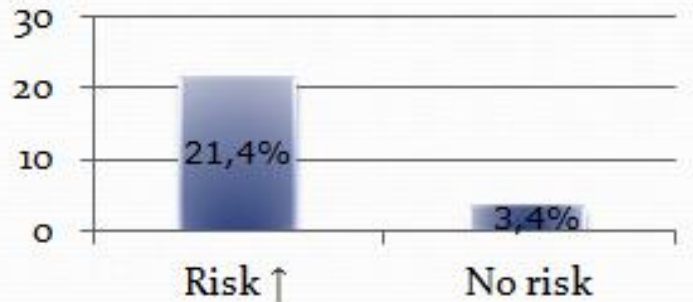

\section{MNA-SF}

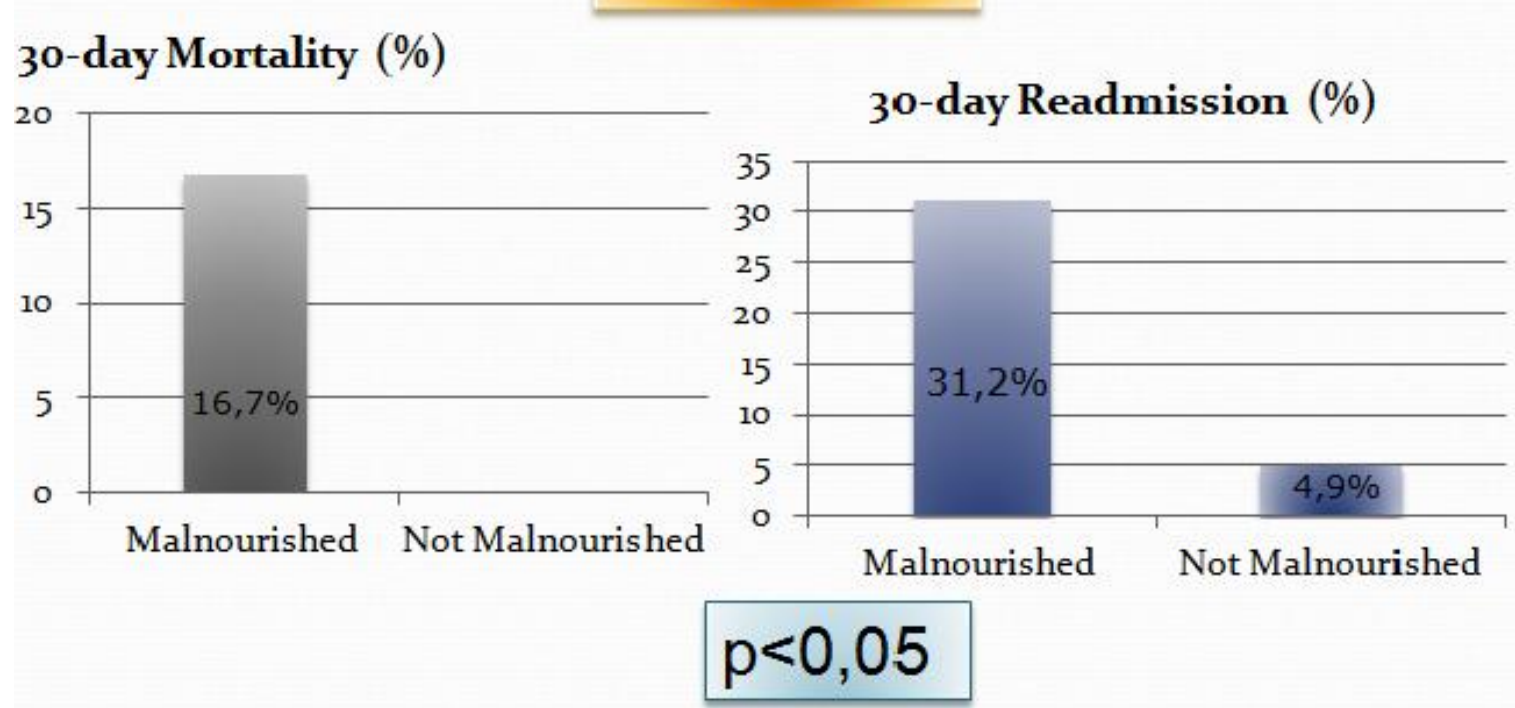

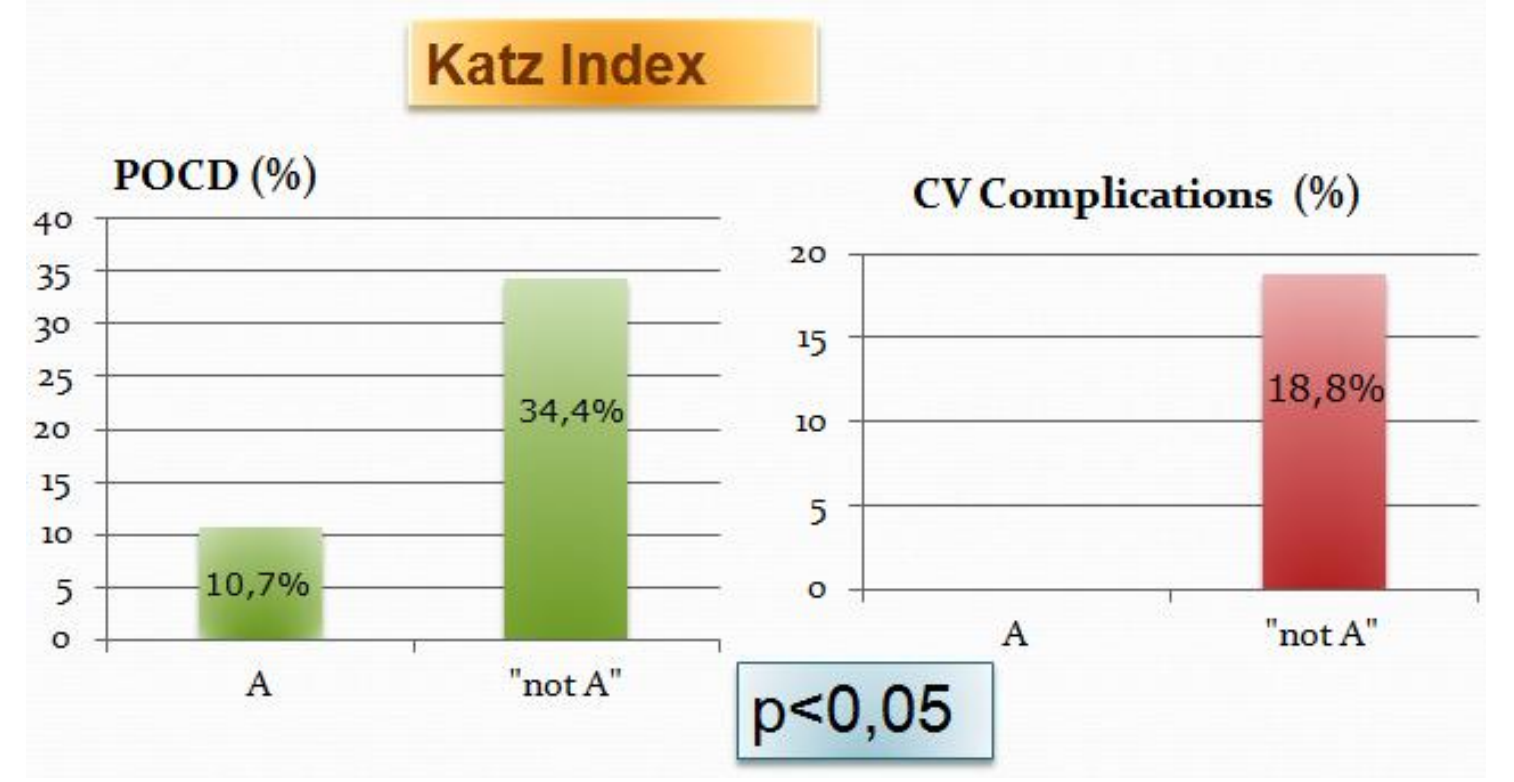

No statistically significant differences between ASA and METs in postoperative complications.

The scores included in the pre-operative assessment guide in patients of advanced age of SCARTD and SCGiG seem to be related to the rate of postoperative complications, mortality and readmission rate within 30 days.

Before demand increases for surgery among elderly patients in their final years, a need arises for a comprehensive perioperative assessment in this heterogenous and highly characteristic population.

This is a pilot study with a small number of patients, but in view of the results, it would be interesting to also extend the follow-up period in order to study long-term morbidity and mortality.

\section{References}

1. Griffiths R . Peri-operative care of the elderly 2014: Association of Anaesthetists of Great Britain and Ireland. Anaesthesia 2014 Jan; 69 Suppl 1:81-98

2. Katz S. Assessing self-maintenance: activities of daily living, mobility, and instrumental activities of daily living. J Am Geriatr Soc. Dec 1983;31(12):721-727.

3. Pfeiffer E. A short portable mental status questionnaire for the assessment of organic brain deficit in elderly patients. $J$ Am Geriatr Soc 1975;23(10):433-41.

4. Rubenstein LZ et al. Screeninf g for undernutrition in geriatric practice: developing the short-form mini-nutritional assessment (MNA-SF). $J$ Gerontol A Biol Sci Med Sci 2001; 56(6): 366-72. 